\title{
Determination of age and growth of Buccinum undatum L. (Gastropoda) off Douglas, Isle of Man
}

\author{
A. E. Kideys \\ Institute of Marine Sciences, Middle East Technical University; P.O. Box 28, \\ 33731 Erdemli, Icel, Turkey* \\ and \\ Port Erin Marine Laboratory, University of Liverpool; Isle of Man, United Kingdom
}

\begin{abstract}
ABSTACT: Age and growth of Buccinum undatum off Douglas (Isle of Man, U.K.) were studied using four independent methods: length-frequency analyses (LFA), operculum analysis (OA), markrecapture experiment (MRE) and laboratory rearing (LR). Within the 16 -month period between February 1989 and June 1990, only the January 1990 sample showed histograms allowing possible age group determination. Among the several length frequency analyses applied to this sample, the growth analysis program MIX calculated that Buccinum reaches mean lengths of 28.5, 45.8, 59.9, 71.5 and $81.0 \mathrm{~mm}$ at the end of its first, second, third, fourth and fifth year, respectively, with an asymptotic length $\left(L_{\infty}\right)$ of $123.8 \mathrm{~mm}$ and Brody growth coefficient $(K)$ of 0.20 . Whilst the results from the LFA were supported by those from the OA and the MRE, growth in the laboratory differed; however, this was expected. Both $\mathrm{K}$ and $\mathrm{L}$ values found in this study are higher than those in two previous studies undertaken for Buccinum in northeastern England and northern France.
\end{abstract}

\section{INTRODUCTION}

For an organic system, growth is simply defined as the measurable increase in weight or length (von Bertalanffy, 1938); yet, for organisms of unknown age its measurement is one of the most challenging problems. Growth occurs due to that part of assimilated food or energy that is retained and incorporated into the biomass of the organism (Kideys \& Hartnoll, 1991). As a result, in gastropod molluscs, increases in shell size take place. Shell growth usually continues, albeit at a decreasing rate, throughout the entire life span (indeterminate growth), or it may stop at some stage (determinate growth), usually when the gastropod reaches sexual maturity (Hughes, 1986). The common whelk, Buccinum undatum, does not stop growing after reaching sexual maturity (Kideys et al., 1993) and therefore shows an indeterminate growth pattern.

Unfortunately, gastropods appear to possess in general much less recognisable annual growth marks as an indicator of age in contrast to many fishes or bivalve molluscs. The most conspicuous growth marks are usually striae or rings in the operculum. However, these have been shown to correspond to the age of the individual in only a very few species (Kubo \& Kondo, 1953). Santarelli \& Gros (1985), using oxygen stable isotopic

* Address for correspondence 
analysis, checked three shells for records of seasonal temperature fluctuations and suggested that formation of operculum striae in $B$. undatum is an annual event.

When age determinations are not convenient, the demographic analysis of size frequency distributions is a very important tool in the study of population dynamics of marine invertebrates (Cerrato, 1980). Methods of determining demographic parameters generally assume that there is a more or less discrete period for recruitment. For example, in temperate waters, reproduction usually occurs once a year (Grant et al., 1987) and, therefore, recruitment is expected to be seasonal; thus a size frequency histogram will be polymodal, representing one or more spawning events (Cerrato, 1980). The main problem is fluctuations in recruitment with time.

The earliest and simplest method of separating the age classes from a size frequency distribution is the "Petersen" method, in which modes in the size histogram are interpreted as single classes. More recently, extensive use has been made of methods which assume that the sizes of individuals of the same age will be normally distributed. The basic idea is that if the distribution function of a mixture of "identifiable" normal distributions is known it can be disaggregated into its components (Yakowitz \& Spagins, 1968 cited in Grant et al., 1987). Graphical methods of analysis proposed by Harding (1949), Cassie (1954) and Bhattacharya (1967) have been extensively used in determining demographic parameters of invertebrate populations (see Cerrato, 1980). However, these methods have recently been criticized severely because of their subjectivity (Macdonald \& Pitcher, 1979; Grant et al., 1987).

Recently, several mathematical procedures have been developed to optimise the fit of the distribution function defining the observed histogram (Macdonald \& Pitcher, 1979; Gayanilo et al., 1988; Sparre et al., 1989). Although these methods reduce the elements of subjectivity in the analysis, allowing confidence limits to be placed around the parameter estimates, they are not entirely objective (Grant et al., 1987).

Mark-recapture experiment (MRE) is another method for determining the age and growth of animals. Yet there is little published literature on individual growth rates of gastropods from MREs (Forster, 1967; Laxton, 1970; Yamaguchi, 1977; Kraeuter et al., 1989). Gastropod molluscs are one of the most difficult groups to age with traditional methods (i.e. growth marks, size frequency analysis), and therefore it was surprising that more MREs were not found in literature for determining growth rates. To my knowledge, there has only been one study to assess growth rates of $B$. undatum by using a MRE (Hancock, 1963; in northeast England). The population of this species off Douglas has a much greater shell length than the northeast England population. Therefore one may also expect different growth parameters.

There has been no previous attempt to observe the growth pattern of $B$. undatum in the laboratory. Although the laboratory growth rate is expected to be different from that in the field, it may provide useful clues (e.g. seasonality in growth or relative growth rates between whelks of different size) to the solution of the problem.

$B$. undatum is one of the most abundant carnivores in the shallow coastal areas of the North Atlantic (Nielsen, 1975; Himmelman \& Hamel, 1993) where it is commercially exploited (Hancock, 1963; Santarelli \& Gros, 1985; Himmelman \& Hamel, 1993; Kideys, 1993). At the present time, no whelk fisheries exist around the Isle of Man, since Buccinum is rarely eaten. However, some fishermen have been exploring export opportunities for this species where a market exists such as France and some far-east countries. 
Therefore, for the management of a possible whelk fishery, determination of its age and growth is very important in order to maintain sustainable exploitation. In the present study, four independent methods were utilized to determine the age and growth of the Buccinum undatum off Douglas: size frequency analyses (LFA), operculum analysis (OA), mark-recapture experiment (MRE) and laboratory rearing (LR).

\section{MATERIAL AND METHODS}

Whelks were sampled from a population off Douglas, Irish Sea, between February 1989 and June 1990. The whelk pots used for sampling consisted of $40 \times 25 \times 25 \mathrm{~cm}$ high cylindrical 5-gallon plastic drums with the top removed. These were weighted down with a cement layer (ca $15 \mathrm{~kg}$ ) at the bottom of each drum, and holes (11 mm diameter) were drilled through the sides to allow diffusion of the bait's smell into the surrounding water. Whelks entered the pots by crawling up the sides and falling through a circular opening with a net tunnel on top. Sampling dates and positions are given elsewhere (Kideys, 1993). Animals were sexed as described in Kideys et al. (1993). After measuring the shell length of each whelk with a vernier caliper (to the nearest $0.1 \mathrm{~mm}$ ), the complete animal was weighed to the nearest $0.01 \mathrm{~g}$.

\section{Length frequency analyses (LFA)}

Shell length and weight measurements were used to construct monthly size frequency distribution diagrams (for males, females, males + females + undetermined). Either a size interval of $2.5 \mathrm{~mm}$ or a gram (being the smallest practical interval) was chosen for size frequency histograms. LFA were performed for the January 1990 sample (with all individuals), as this sample showed clear modes in the histogram.

Several graphical and mathematical methods of separating age classes from a length frequency distribution were applied to the data. In the first attempt, major modes of the frequency distribution were assumed to represent the age groups. Shell length frequency distribution was also analysed graphically using the probability paper as described by Harding (1949). The mean lengths (for January 1990) obtained from these methods were used to find the asymptotic length $\left(\mathrm{L}_{\infty}\right)$ and Ford's growth coeffient $(\mathrm{k})$ using a FordWalford plot (Walford, 1946). The Brody growth coefficient was then calculated using the equation $-\ln \mathrm{k}=\mathrm{K}$ (Ricker, 1975).

Age classes were also separated using two different mathematical models, i.e. MIX (Interactive Program for Fitting Mixtures of Distributions) developed by Macdonald \& Pitcher (1979) and ELEFAN (Electronic Length Frequency Analysis) developed by Gayanilo et al. (1988). In both models, the parameters of the von Bertalanffy equation (i.e. $L_{t}=L_{\infty}-\left(1-e^{-K\left(t-t_{\infty}\right)}\right)$ are computed with their standard errors, where $L_{t}$ is the estimated length at age $t, t_{o}$ is the hypothetical age that the animal would have been at zero length, and $L_{\infty}$ and $K$ are as explained above (Ricker, 1975).

\section{Mark-recapture experiment (MRE)}

Estimation of growth parameters of Buccinum was attempted from a MRE using Jones' (1976) method. In this method, the increment per unit time (y) and the midpoint of 
each growth period were calculated for each recaptured animal. The slope of $\mathrm{x}$ and $\mathrm{y}$ is an estimate of $\mathrm{K}$ (growth rate). On several occasions between February and May 1989, a total of 3114 animals were tagged and released. Tagging was conducted by drilling and wiring a plastic tag onto the near edge of the larger whorl of the shell (for details see Kideys, 1994).

\section{Operculum analysis (OA)}

An attempt was also made to count the number of operculum striae with the naked eye. Three different groups of whelks were identified according to the clarity of opercular striae. The first group was defined as "unclear", since opercular striae were not distinguishable. The second group was labelled "reasonably clear", since the opercular striae were discernible, but their numbers could change depending on the person counting. The third group was termed "clear", since the opercular striae were well defined. This last group included those operculae with unmistakably no striae.

\section{Laboratory rearing (LR)}

In addition to the determination of laboratory growth, this experiment was designed so that the effect of tagging on the growth of Buccinum could be evaluated (see Kideys, 1994 for details of tagging and experimental design). The experiment was carried out using 50 tagged and 50 untagged whelks ( 5 females and 5 males from each size group $[30-39,40-49,50-59,60-69,70-79])$ sampled in December 1990 from the study area. Only 10 animals ( 1 tagged and 1 untagged from each of 5 size groups) were put into each ca 13-litre Perspex tank with continuous water flow. Eack tank was provided with excess food (3-4 scallops, Chlamys opercularis) every three days. The length and weight of whelks were recorded at approximately monthly intervals until November 1991. The mortality was low during a 12-month experimental period (only 4 tagged and 6 untagged dead from a total of 100 whelks) and data only from surviving whelks were utilized in the determination of Buccinum growth.

In order to see if opercular rings are laid annually, the number of clear striae in the operculum of tagged whelks was also recorded at the start and end of the experiment.

\section{RESULTS}

\section{Length frequency analyses (LFA)}

Monthly size (both length and weight) frequency histograms of female, male and all whelks were plotted separately for the period between February 1989 and June 1990, but shown in Figure 1 only for all whelks. Sex ratios of the population from combined samples indicated a small surplus of females, with a male:female ratio of 1:1.14 (Kideys et al., 1993). A total of 10975 animals were used to construct size frequency histograms. The smallest and largest whelks had a length of $10.0 \mathrm{~mm}$ and $125 \mathrm{~mm}$, respectively, during the sampling period in the study area. The length histograms showed generally a single peak around $70-80 \mathrm{~mm}$ (Fig. 1). Approximately $84 \%$ of the samples comprised animals larger than $50 \mathrm{~mm}$ in shell length. All histograms displayed negative skewness. 
The timing of recruitment was not clear from monthly size frequency histograms. However, when running averages of monthly ratios of whelks measuring $<50 \mathrm{~mm}$ (fully juveniles) to $>50 \mathrm{~mm}$ were plotted over the sampling period, the timing of recruitment became more discernible (Fig. 2). Although recruitment to the population was an all year round event, there appears to be an escalation from March 1989 to September 1989. The highest representation of younger size groups was between September 1989 and March 1990.

It is interesting to note that out of 16 monthly size frequency histograms, only one sample (January 1990) showed relatively clear modes of possible age classes (Fig. 1). Therefore, this histogram has been used to discriminate age classes of whelks using several graphical and mathematical methods. The Petersen method of analysing the shell length frequency distribution of the January (1990) sample suggested that the population of Buccinum undatum off Douglas was made up of five age classes (Table 1). When the modes from this simple graphical method were used as mean lengths of age groups for the Ford-Walford plot, an asymptotic length $\left(\mathrm{L}_{\infty}\right)$ value of $123.7 \mathrm{~mm}$ and Brody coefficient value $(\mathrm{K})$ of 0.20 were obtained.

The January (1990) sample was also analysed using the probability paper according to Harding (1949). This also showed five modes corresponding to age groups. In addition to mean length at age, this method also gives standard deviation for each age group (Table 1). Using these data, the Ford-Walford plot gave an $\mathrm{L}_{\varkappa}$ value of $125 \mathrm{~mm}$ and $\mathrm{K}$ value of 0.22 .

Results obtained from the simple graphical method have been used as initial input data for MIX. After several iterations, a good fit (chi squared $=19.745 ; \mathrm{P}=0.956 ; \mathrm{df}=32$ ) with five components was obtained (Fig. 3). MIX calculates a mean, standard deviation and proportion for each component (Table 1). When the means were constrained to lie along a von Bertalanffy growth curve, an $\mathrm{L}_{\infty}$ value of $123.8 \mathrm{~mm}(\mathrm{~S} . \mathrm{E} .=8.58 \mathrm{~mm})$ and a $\mathrm{K}$ value of 0.20 (S.E. $=0.025$ ) were found.

Table 1. Analyses of shell length frequency distibution of the population of $B$. undatum (January 1990 sample, $\mathrm{n}=705$ ) off Douglas using several methods. Estimated mean shell length (mm, $\mu$ ), standard deviation $(\mathrm{mm}, \mathrm{s})$, percentages $(\mathrm{p})$ for each mode

\begin{tabular}{|c|c|c|c|c|c|c|c|c|}
\hline Method & $\begin{array}{l}\text { Para- } \\
\text { meter }\end{array}$ & 1 & 2 & $\begin{array}{c}\text { Modes } \\
3\end{array}$ & 4 & 5 & $\mathrm{~L}_{x \mathrm{c}}$ & $\mathrm{K}$ \\
\hline Petersen & $\mu$ & 25.0 & 42.5 & 57.5 & 70.0 & 80.0 & 123.7 & 0.20 \\
\hline \multirow[t]{3}{*}{ Probability paper } & $\mu$ & 23.8 & 42.5 & 61.0 & 73.3 & 81.3 & 125.0 & 0.22 \\
\hline & s & 5.0 & 5.0 & 7.5 & 4.7 & 5.5 & & \\
\hline & $\mathrm{p}$ & 9.5 & 21.5 & 28.0 & 23.7 & 17.3 & & \\
\hline \multirow[t]{2}{*}{ MIX } & $\mu$ & 23.4 & 41.4 & 56.4 & 68.2 & 78.2 & 123.8 & 0.20 \\
\hline & $\mathrm{s}$ & 5.6 & 5.4 & 4.3 & 3.7 & 5.5 & & \\
\hline \multirow[t]{4}{*}{ ELEFAN } & $\mathrm{p}$ & 10.2 & 20.8 & 17.9 & 21.5 & 29.5 & & \\
\hline & $\mu$ & 26.4 & 44.7 & 60.2 & 71.8 & 81.1 & 124.0 & 0.22 \\
\hline & s & 6.7 & 4.4 & 6.4 & 2.6 & 5.7 & & \\
\hline & $\mathrm{p}$ & 11.5 & 19.0 & 25.4 & 18.3 & 25.7 & & \\
\hline
\end{tabular}



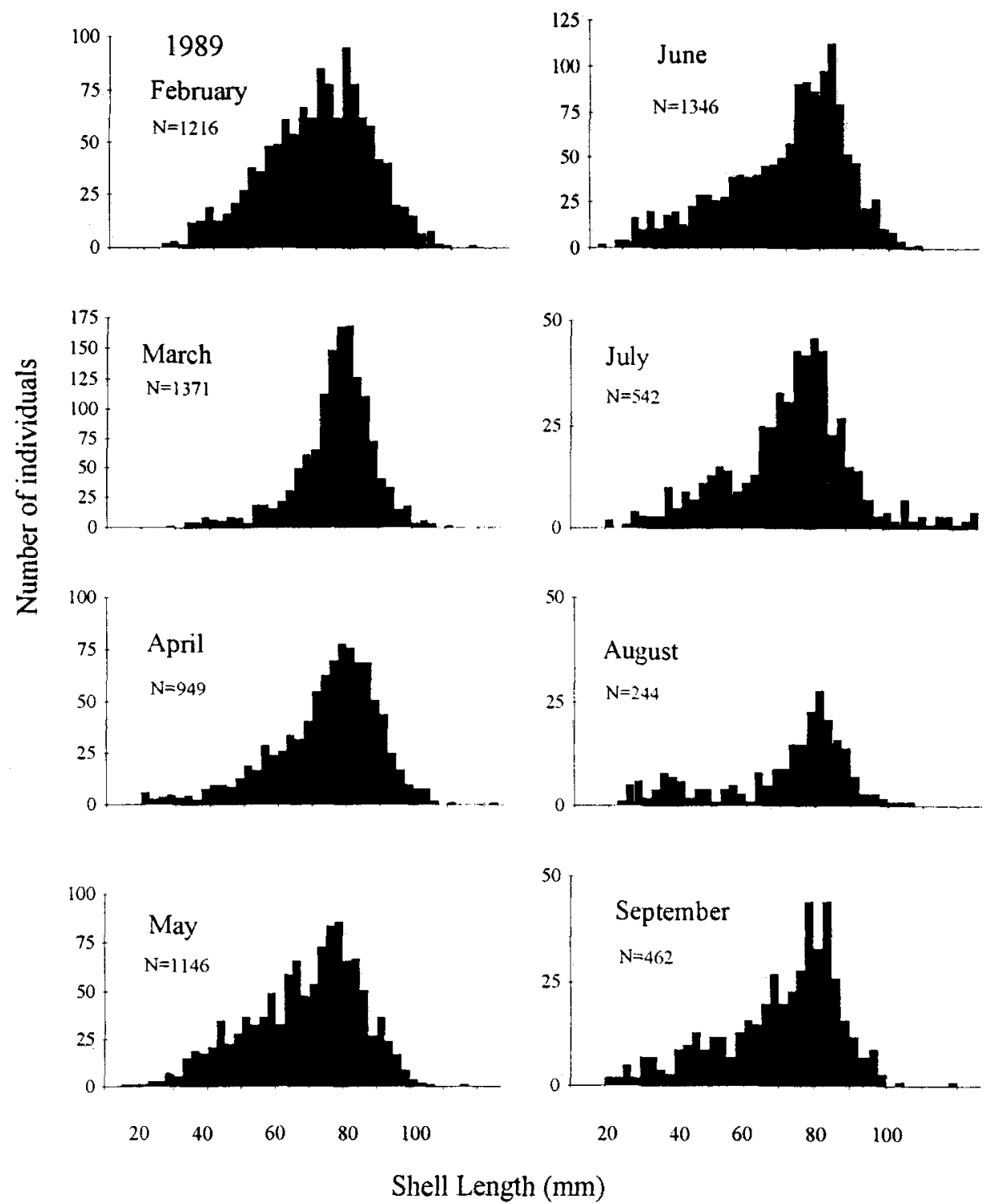

Fig. 1. Monthly length frequency distributions of Buccinum undatum from February 1989 to June 1990

The ELEFAN, computer length frequency analysis program, which uses the Bhattacharya method to separate age groups appeared to be less efficient than MIX for the population of $B$. undatum off Douglas. The mean, standard deviation and population number of each component were given in Table 1. The asymptotic length and growth rate found by ELEFAN were $124 \mathrm{~mm}$ and 0.22 , respectively, for the January (1990) sample. 

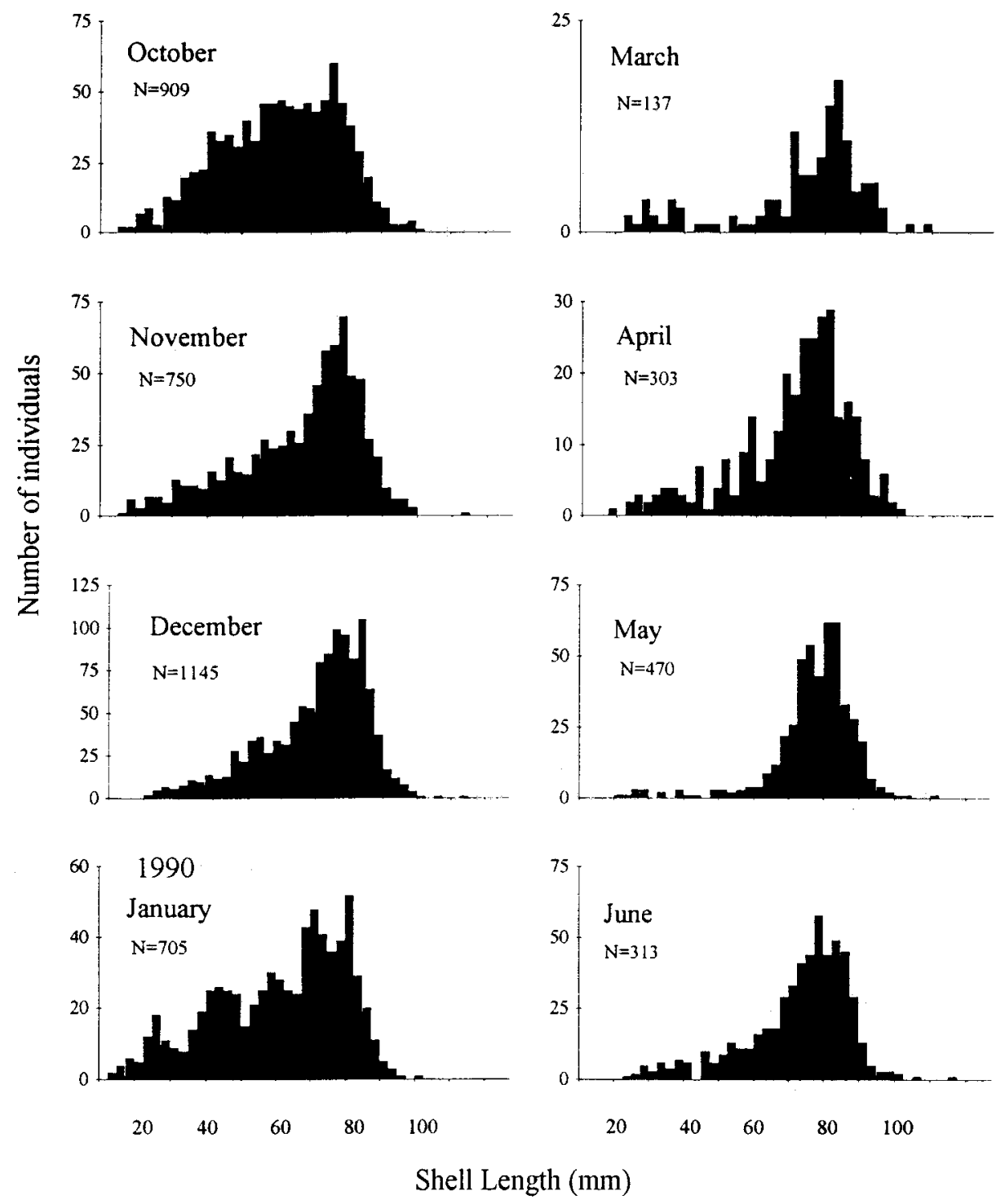

Shell Length (mm)

Fig. 1. continued

All methods tested revealed a good fit of the von Bertalanffy growth curve for the population of Buccinum off Douglas. The values of asymptotic lengths $\left(\mathrm{L}_{\infty}\right)$ and Brody coefficients $(\mathrm{K})$ obtained from these methods were quite close to each other. However, it should be noted that all initial input values were based on data obtained from the Petersen method which might be the main reason for similarity between the results from these different methods. Grant et al. (1987) stated that if the Petersen method does not work, accurate estimates of demographic parameters are unlikely to be obtainable using 


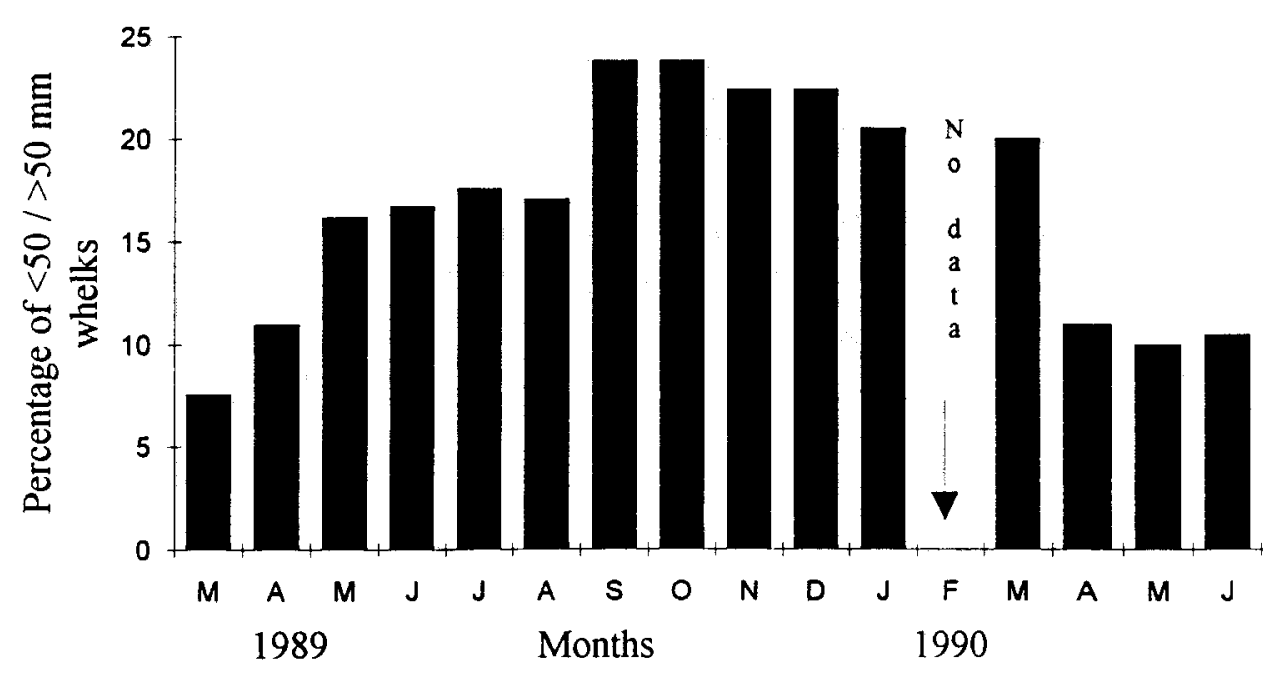

Fig. 2. Running average of monthly variations in percentage of whelks measuring $<50 \mathrm{~mm}$ to $>50 \mathrm{~mm}$ during the sampling period (February 1989-June 1990). No data for February

more rigorous methods. The finding is that all four methods were applicable to this histogram. All these methods have been used quite successfully in resolving size frequency distributions into age classes for some animal groups (see Cerrato, 1980 and Sparre et al., 1989). However, graphical methods including the Bhattacharya method have recently been severely criticized (Grant et al., 1987). The difficulty and objectivity of separating modes by visual inspection have also been pointed out by Sparre et al. (1989), which was confirmed once more in the present study, especially for the probability paper method. Grant et al. (1987) suggest the use of MIX from among the LFA as this technique gives the confidence intervals for the estimated values.

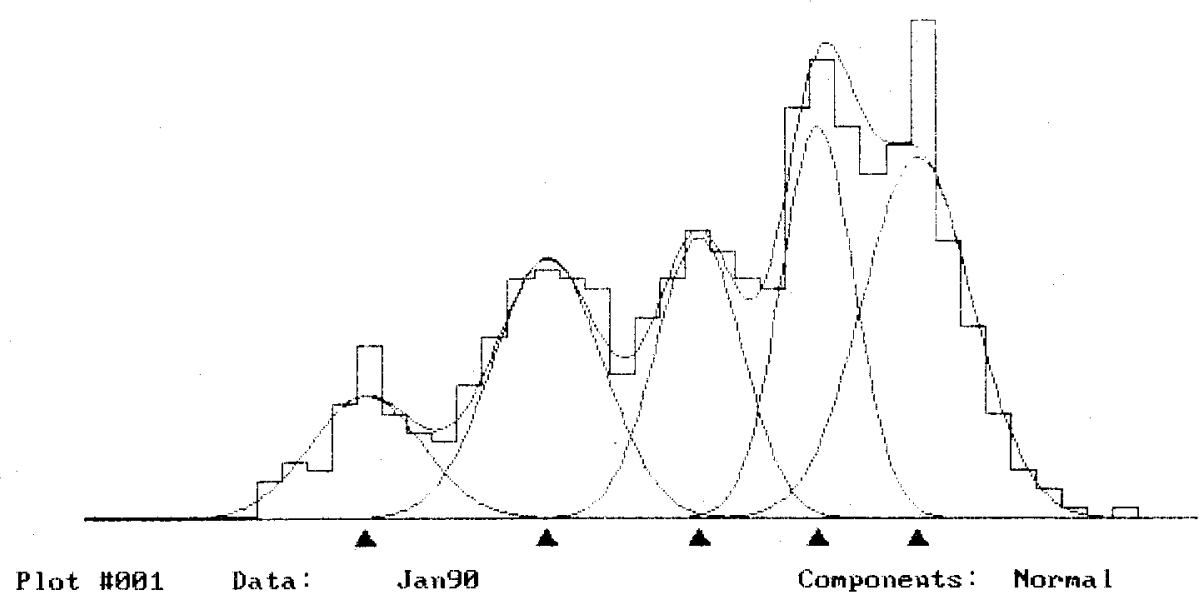

Fig. 3. Curve fitting of MIX on length frequency histogram of Buccinum undatum off Douglas (the January 1990 sample, all individuals included) 
The modes (from MIX) obtained for the January 1990 sample were thus assumed to reflect age groups. However, since hatching usually occurs in April-May (see Kideys et al., 1993), the first mode in January represents $\sim 0.75$ years of age. The second mode represents $\sim 1.75$ years of age, the third mode $\sim 2.75$ years of age and so on. Therefore, an adjustment was applied to obtain the length at ages 0, I, II, III etc. years using the von Bertalanffy equation. The parameter $t_{0}$ was estimated from least squares regression of $\ln$ $\left(\mathrm{L}_{\infty}-\mathrm{L}_{\mathrm{t}}\right)$ on age (Ricker, 1975). This was:

$$
\mathrm{t}_{\mathrm{o}}=\left(\text { intercept-ln } \mathrm{L}_{\infty}\right) / \mathrm{K}=(4.7567-4.8187) / 0.20=-0.310 .
$$

By substituting this value in the von Bertalanffy equation, the lengths at the end of completed age 0 , I, II, III etc. were calculated (Table 2). The mean length of the whelks increased with age. $B$. undatum reached a mean length of $28.5 \mathrm{~mm}$ after its first year, $45.8 \mathrm{~mm}$ at the end of its second year, $59.9 \mathrm{~mm}$ at the end of its third year, 71.5 at the end of its fourth year and $81.0 \mathrm{~mm}$ at the end of its fifth year following hatching. The mean length $\left(L_{o}\right)$ of the whelk at age $t=0$ would be $7.4 \mathrm{~mm}$ assuming growth occurred according to the von Bertalanffy equation.

Table 2. Comparison of length at the end of age from different methods (LFA length frequency analysis, OA operculum analysis, LR laboratory rearing)

\begin{tabular}{|c|c|c|c|c|c|c|c|c|}
\hline & \multicolumn{5}{|c|}{ Completed Age (yr) } & \multirow[b]{2}{*}{$L_{\approx}$} & \multirow[b]{2}{*}{$\mathrm{K}$} & \multirow[b]{2}{*}{$t_{0}$} \\
\hline & 0 & I & II & III & IV & & & \\
\hline LFA $(n=705)$ & 28.5 & 45.8 & 59.9 & 71.5 & 81.0 & 123.8 & 0.20 & -0.31 \\
\hline$O A \cdot(n=251)$ & 33.6 & 47.8 & 59.5 & 69.2 & 77.2 & 115.5 & 0.19 & -0.81 \\
\hline $\operatorname{LR}^{\prime} \cdots(\mathrm{n}=42)$ & 35.2 & 56.2 & 70.2 & 79.4 & 85.6 & 97.7 & 0.41 & -0.09 \\
\hline
\end{tabular}

\section{Mark-recapture experiment (MRE)}

Only thirty four out of 3114 tagged whelks were recaptured over a one-year period of fishing. Estimates from mark-recapture data yielded highly variable results. A high percentage (over $50 \%$ ) of individuals exhibited no growth or negative growth rates. Most of these individuals did not reflect the annual growth cycle, because they were recaptured only a few months after release. In addition to this, the apex of two recaptured whelks were clearly noticed to be broken, resulting in negative growth values. Since the tagging method applied is shown to hinder the growth of whelks very significantly during the first few months following its application, only animals recaptured at least six months later were considered for the determination of growth rate from MRE. However, merely nine animals were recaptured six months after release. Jones' (1976) method, applied to data for five individuals showing a positive increment, gave a low coefficient of determination value $\left(R^{2}=0.717 ; P>0.05\right)$ indicating that the determination of growth parameters from this method in this experiment was impossible. However, individual growth increments obtained from the MRE were found to approximate findings of the LFA. 
The smallest recaptured individual showed an increase of $7.0 \mathrm{~mm}$ in shell length in 0.53 years (from 39.7 to $46.7 \mathrm{~mm}$ ). A whelk measuring $59.9 \mathrm{~mm}$ during marking grew $5.2 \mathrm{~mm}$ in 0.57 years. The other three whelks measuring $68.1,69.0$ and $71.1 \mathrm{~mm}$ were 85.1 (after 1.63 years), 79.1 (after 1.12 years) and 74.7 (after 0.53 years) $\mathrm{mm}$, respectively.

\section{Operculum analysis (OA)}

Whelks sampled between February 1989 and June 1990 were checked for their operculum striae. Of the 10975 whelks examined 5661 (52\%) showed clear or reasonably clear striae-like structures in their operculum (Fig. 4). Only $1731(16 \%)$ of these had clearly countable striae (Fig. 4). The highest number of striae was eleven. Although a trend of increasing number of striae with increasing length was observed, there appeared to be large overlaps in length-at-age. For example, individuals with two and three clearly visible striae had length ranges of 26.4-86.8 mm and 34.9-124.5 mm, respectively.

Von Bertalanffy growth parameters were calculated using 251 individuals with clear striae in their operculum from the January 1990 sample. Since hatching occurs in AprilMay, a correction was made for the age data as explained above in the LFA section. The length values calculated for each age correlated well with respective data obtained from the LFA (Table 2). This was supported by a two-tailed paired-sample t-test ( $P>0.05$; Zar, 1984). In parallel, the similarity of the length-at-age data between the two methods, the growth parameters obtained by them were also found to approximate closely to each other (Table 2).

Twenty seven out of 50 tagged whelks had clear striae at the beginning (13th December 1990) of the laboratory experiment. However, only seven whelks still had clear striae at the end of the experiment (16th November 1991), of which the striae number of 4 whelks was observed to have increased by 1 as expected. Whilst one whelk showed no increase in the number of its operculum striae, there was a decrease by 2 in one other whelk (from 2 to 0 striae). The highest difference occurred in the operculum number of the last whelk, with an increase from 0 to 3 striae in nearly 12 months of experimental period.

\section{Laboratory rearing (LR)}

With 6-10 whelks, the monthly average length of each size group was calculated for the period of December 1990 to November 1991. In order to compare the growth rate from the laboratory experiment with that obtained by the LFA, the following procedure was applied. It was assumed that when the sample for the laboratory experiment was first taken, growth parameters of individuals could be expressed with the same parameters as found by the LFA. The corresponding age $(t(L))$ for the average length of each size-group was thus calculated by using growth parameters obtained from the LFA (Table 3). Since the laboratory experiment was for one year, the length at the end of the experiment would be $t+1$. Using final length and age, new growth parameters were calculated which describe that part of the whelk growth which occurred in the laboratory. The $\mathrm{L}_{\infty}$ and $\mathrm{K}$ values were thus found as $97.7 \mathrm{~mm}$ and 0.41 , respectively. By substituting these new parameters in the von Bertalanffy equation, the lengths at different ages were calculated (Table 2). It appeared that the whelks kept in the laboratory grew faster and reached 

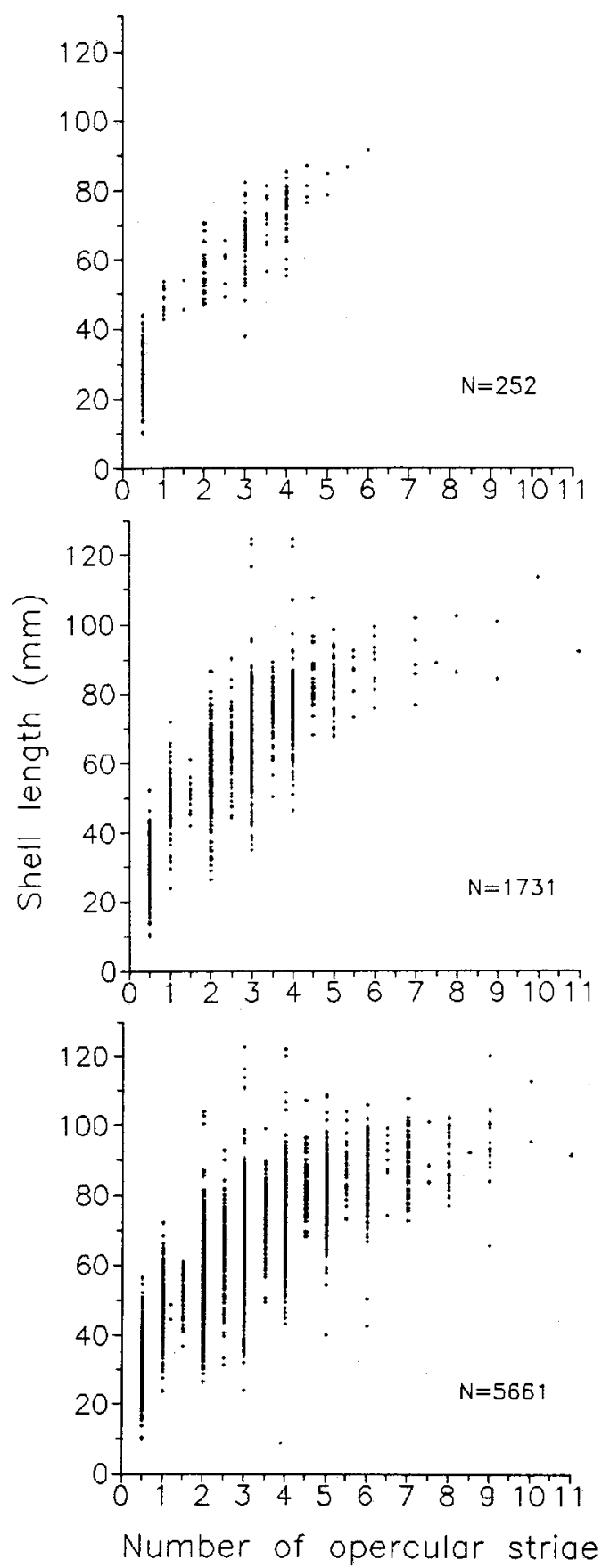

Fig. 4. The relationship between the number of (clear and reasonably clear) striae on the operculum and length of the whelk. a: clear operculum from the January 1990 sample (top); b: clear operculum from combined samples of 16 months (middle); c: clear + reasonably clear operculum from combined samples of 16 months (bottom) 
larger sizes in the same period than those in the field (which was revealed via LFA, MRE and $O A)$. The results on growth from the LFA and the LR were significantly different (two-tailed paired-sample t-test, $\mathrm{P}<0.002$ ).

Table 3. Calculation of the von Bertalanffy parameters from laboratory rearing (LR). Using data obtained at the end of experiment, $\mathrm{L}_{s}, \mathrm{~K}$ and $\mathrm{t}_{\mathrm{o}}$ values and length at age were computed as given in Table 2

\begin{tabular}{|c|c|c|c|c|c|}
\hline \multirow{2}{*}{$\begin{array}{l}\text { Size group } \\
(\mathrm{mm})\end{array}$} & \multirow[t]{2}{*}{$\mathrm{n}$} & \multicolumn{2}{|c|}{ At the start of experiment } & \multicolumn{2}{|c|}{ At the end of experiment } \\
\hline & & $\begin{array}{l}\text { Average length } \\
\text { (mm) }\end{array}$ & $\begin{array}{l}\text { Age } \\
(y r)\end{array}$ & $\begin{array}{l}\text { Average length } \\
(\mathrm{mm})\end{array}$ & $\begin{array}{l}\text { Age } \\
(y r)\end{array}$ \\
\hline $30-39$ & 9 & 35.7 & 1.39 & 59.8 & 2.39 \\
\hline $40-49$ & 8 & 45.6 & 1.99 & 67.2 & 2.99 \\
\hline $50-59$ & 10 & 56.4 & 2.73 & 74.6 & 3.73 \\
\hline $60-69$ & 9 & 64.5 & 3.37 & 81.2 & 4.37 \\
\hline $70-79$ & 6 & 75.4 & 4.39 & 86.2 & 5.39 \\
\hline
\end{tabular}

\section{DISCUSSION}

The $2.5 \mathrm{~mm}$ size interval with approximately 46 length groups chosen for this study should have been sufficient for LFA. Sparre (1989) suggests one should use as many as possible, e.g. 50-100 length groups where possible. Thus, the number of size groups used in this study is quite close to this suggestion. The range of sample sizes during the study period varied between 137 individuals (in March 1990) and 1371 individuals (in April 1989). The suggested minimum number of 50 individuals (Macdonald \& Pitcher, 1979) for each age group was generally met.

Probably because of pot selection against juveniles, the length frequency histogram of the whelks always showed negative skewness. There are many documented examples of such adult-predominant-size-frequency distributions in gastropods due to poor representation of juveniles (Kohn, 1968; Frank, 1969; Yamaguchi, 1977). It was not suprising that the smallest whelk caught was $10.0 \mathrm{~mm}$ as the pots used for sampling had holes which were $10 \mathrm{~mm}$ in diameter. However, still a discernible recruitment was expected as Buccinum undatum has been shown to have a distinct seasonal cycle of reproduction (see Kideys et al., 1993). The reason for the subtle recruitment may be due to some other factors. For example, smaller animals may have a different diet preference in comparison to larger animals. In this study, dogfish flesh and scallops were generally used as bait which was observed to be a preferred food (as bait) by adult whelks in the laboratory (pers. comm. with Mrs. S. Duncan, Port Erin Marine Laboratory, Isle of Man, UK). Whilst the diet of adults is well known (Nielsen, 1975; Taylor, 1978; Himmelman \& Hamel, 1993), there are no studies on the food preference of juveniles of $B$. undatum. Also, smaller whelks do not move as fast as larger individuals especially when moving towards bait because of the difference in the foot size. This could affect the proportions of small to large whelks in the sampling gear and may cause bias in the sampling in favour of larger 
animals. The increase in the ratio of whelks measuring $<50 />50 \mathrm{~mm}$ from May 1989 to January 1990 could suggest a continuous recruitment, which may be because of differences in the growth rates of juveniles. Unfortunately there are no studies on the growth of juveniles of Buccinum.

In this study there was a decrease in catch size during 1990 in comparison to that for the same months of 1989 at the beginning of sampling. This could be explained by consistent pot sampling causing a decrease in the common whelk population in the study area. Besides this, fluctuations in catch size and composition throughout the sampling period have been suggested to be due to biological (such as mating, spawning, feeding, recruitment, immigration and/or emigration) and physical (such as ambient temperature and direction and speed of local currents) factors (Kideys, 1993).

It is not easy to explain why the January (1990) sample showed somewhat discernible modes in the length frequency which could be assigned to age groups while the other fifteen months' samples did not. It is worth noting that January is the peak spawning period for Buccinum with an aggregation of the population occurring in the coastal area off Douglas (Kideys et al., 1993). January's sample, being "the easiest" (Sparre et al., 1989), was used for the LFA's (see Table 1). The values of parameters found by these methods were all comparable. It should be noted that although results were based on the assumption of the existence of five modes (which was revealed by the Petersen method), the number of age groups could have been more than five, perhaps 11 (which was the maximum number of opercular striae observed). It is a well known fact that generally the growth rate of animals decreases with age. Consequently, the modes of younger age groups catch up with the older, and several overlapping modes are accumulated at the right end of the histogram. It has been pointed out (Grant et al., 1987) that it is difficult, if not impossible, to determine the number of age groups that are present using any method of size frequency analysis, especially if, as is often the case, older age groups are amalgamated.

The irregular growth pattern obtained from the mark-recapture results is not unusual for gastropods. For example, Kraeuter et al. (1989) observed a large variation in individual growth rates of the conch, Busycon carica, from a MRE. In his study with the same species, Magalhaes (1948) reports that "even immature specimens showed no change in size in a year, or two, in the field under apparently favourable conditions". In this study, there was also a high percentage of negative growth, but many smaller incremental losses may be due to measurement error. Two individuals were observed which had lost some of their shell apex when recaptured. So it is possible that some of the negative growth rates may be due to continual erosion of shell from the apex (Yamaguchi, 1977) or breakage of the shell during feeding (Kraeuter et al., 1989). Buccinum and other heavily shelled whelks have been reported to use their shell in feeding and often chip the outer edge of the body whorl (Nielsen, 1975). In order to estimate growth rate from the MRE therefore, Kraeuter et al. (1989) suggest a correction factor for the negative growth. However, accurate determination of this factor needs further experimentation which was not considered in this study.

In the Irish Sea, hatching of eggs in the field occurs between April and May (Kideys et al., 1993), therefore an arbitrary birth date of April/May was assigned. This time also coincided with the tagging experiment release date. The smallest whelk was recaptured after 0.53 years and grew from 39.7 to $46.7 \mathrm{~mm}$ (April-September 1989) denoting a 
$13.2 \mathrm{~mm}(=7.0 / 0.53)$ increase for one year (assuming a constant growth rate). This value is only $6 \%$ lower than the $14.1 \mathrm{~mm}$ increment found for similar sized whelks (45.8 to $59.9 \mathrm{~mm}$ from age 1 to 2 i Table 2) from the LFA. Likewise, a whelk which measured $59.9 \mathrm{~mm}$ during marking was observed to have reached $65.1 \mathrm{~mm}$ on recapture after 0.57 years denoting a $9.1 \mathrm{~mm}$ increment for the complete year. LFA showed that the same sized whelks (59.9 mm or 2 years old) grow $11.6 \mathrm{~mm}$ in one year (Table 2) which is $22 \%$ higher than the yearly increment value of an equally sized, marked individual. The annual average growth increment of three other whelks (average size $69.4 \mathrm{~mm}$ ) was $8.1 \mathrm{~mm} ; 15 \%$ lower than that obtained from LFA for a similar sized whelk $(71.5 \mathrm{~mm}$ or 3 years old).

It was not unexpected that results obtained from the MRE are lower (6-22\%) than those obtained from the LFA. Kideys (1994) observed that following tagging, whelks spent extra effort (and energy) to repair the hole and to cover the wire (used for fixing the tag onto the shell) with shell material during the first few months. Although, after a few months, instantaneous growth rate may catch up, the cumulative growth did not approximate that of untagged whelks even 10 months after tagging. Therefore, when one considers the effect of tagging on the overall growth of whelks, the difference of $6-22 \%$ seems realistic, and hence it can be concluded that results from the MRE support those from the LFA.

It is unfortunate that overall only a small percentage $(16 \%)$ of whelks showed clear striae in their operculum, as this could have been an easy indicator of age. Santarelli \& Gros (1985) did not give any information about the percentage of operculum with clear striae from their study area, the "Normano-Breton" Gulf, in the western English Channel off northern France. It should also be noted that Santarelli \& Gros (1985) used only three individuals in their correlation of number of opercular striae with environmental temperature. Oxygen isotope analysis was used to validate their suggestion that opercular striae were laid down annually in Buccinum.

There was also great variation between the lengths of whelks showing the same number of striae. The 26.4-86.5 mm size range generally makes up more than $95 \%$ of the Buccinum population off Douglas. Animals of this size range could have had two striae in their operculum. This makes it difficult to accept that number of striae is proportional to age of the whelk. However, the general trend of increasing number of striae with increasing length seems logical with respect to age (Fig. 4). The results obtained from clear striae (using the January 1990 sample) were also found to be in good agreement with those from the LFA. The $\mathrm{L}_{\infty}$ value of $115.5 \mathrm{~mm}$ and $\mathrm{K}$ value of 0.19 estimated by the former are very close to $123.8 \mathrm{~mm}$ and 0.20 , respectively, obtained by the LFA. When reasonably clear operculae were included, the $\mathrm{L}_{\infty}(98.5 \mathrm{~mm})$ and $\mathrm{K}(0.27)$ values departed from those found by LFA, indicating clarity of striae to be an important factor in the accurate determination of growth parameters from this method.

The increase in the number of clear striae by 1 in 4 out of 7 operculae $(57 \%)$ in a oneyear laboratory experiment is another result supporting the idea that opercular striae reflect the age of the whelk. However, because of the uncertainties in the accuracy in striae number, it is suggested to analyse a high number of clear operculae to determine growth parameters from this method. Whilst results from OA and MRE were found to confirm the growth parameters obtained by the LFA, those from the LR differed greatly. This is not surprising, as whelks kept in the laboratory had a regular supply of excess 
food: a situation which undoubtedly contrasts with the field conditions, resulting in faster growth.

The results found in this study were compared with the results of Hancock (1963) from a MRE and Santarelli \& Gros (1985) from the OA. The Brody growth coefficient value $(\mathrm{K})$ of 0.20 obtained is higher than those obtained for northeastern England $(0.08$; Hancock, 1963) and for northern France (0.13; Santarelli \& Gros, 1985). The reason for the low figure obtained in northeastern England could partly be due to the effect of marking which was not studied. Similar to growth rates, the $\mathrm{L}_{\infty}$ values of $\sim 68$ and $112.5 \mathrm{~mm}$ found for northeastern England and northern France, respectively, were less than here $(123.6 \mathrm{~mm})$, suggesting that the Buccinum population off Douglas has a potential to reach a larger size than the northeastern England and northern France populations. Whelks as large as $164.6 \mathrm{~mm}$ have been measured in samples obtained from the west of the Isle of Man (pers. observation) compared to the $125 \mathrm{~mm}$ maximum length found from the study area (east of the Isle of Man) indicating that, even between relatively close areas (i.e. east and west of the Isle of Man), the growth parameters may differ considerably. Therefore, for managerial purposes when the fishery starts, the growth parameters of other populations around the Isle of Man should also be determined.

Acknowledgements. My thanks go to Prof. T. Norton of Port Erin Marine Laboratory (University of Liverpool) for providing the necessary laboratory facilities, Dr R. D. M. Nash for his supervision during the study, and to Dr S. Hawkins for introducing me to the 'Bucy'.

\section{LITERATURE CITED}

Bertalanffy, L. von, 1938. A quantitative theory of organic growth (inquiries on growth laws. II). Human Biol. 10, 181-213.

Bhattacharya, C. G., 1967. A simple method of resolution of a distribution into Gaussian components. - Biometrics 23, 115-135.

Cassie, R. M., 1954. Some uses of probability paper in the analysis of size frequency distributions. Aust. J. mar. Freshwat. Res. 5, 513-522.

Cerrato, R. M., 1980. Demographic analysis of bivalve populations. In: Skeletal growth of aquatic organisms. Ed. by D. C. Rhoads \& R.A. Lutz. Plenum Press, New York, 417-465.

Forster, G. R., 1967. The growth of Haliotis tuberculata: Results of tagging experiments in Guernsey. - J. mar. biol. Ass. U.K. 47, 287-300.

Frank, P. W., 1969. Growth rates and longevity of some gastropod mollusks on the coral reef at Heron Island. - Oecologia 5, 232-250.

Gayanilo, F. C. Jr., Soriano, M. \& Pauly, D., 1988. A draft guide to the COMPLEAT ELEFAN. ICLARM Software Project 2.: $65 \mathrm{pp}$. and 10 diskettes.

Grant, A., Morgan, P. J. \& Olive, P. J. W., 1987. Use made in marine ecology of methods for estimating demographic parameters from size/frequency data. - Mar. Biol. 95, 201-208.

Hancock, D. A., 1963. Marking experiments with the commercial whelk (Buccinum undatum). Spec. Publs int. Commn NW Atlantic Fish. 4, 176-187.

Harding, J. P., 1949. The use of probability paper for the graphical analysis of polymodal frequency distributions. - J. mar. biol. Ass. U.K. 28, 141-153.

Himmelman, J.H. \& Hamel, J.-R., 1993. Diet, behaviour and reproduction of the whelk Buccinum undatum in the northern Gulf of St Lawrence, eastern Canada. - Mar. Biol. 116, 423-430.

Hughes, R. N., 1986. A functional biology of marine gastropods. Croom Helm, London, $245 \mathrm{pp}$.

Jones, R., 1976. The use of marking data in fish population analysis. - FAO Fish. tech. Pap. 153, 42.

Kideys, A. E., 1993. Estimation of the density of Buccinum undatum (Gastropoda) off Douglas, Isle of Man. - Helgoländer Meeresunters. 47, 35-48. 
Kideys, A. E., 1994. Effect of tagging on the growth rate of the neogastropod, Buccinum undatum in the laboratory. - Fish. Res. 20, 283-289.

Kideys, A. E. \& Hartnoll, R. G., 1991. Energetics of mucus production in the common whelk Buccinum undatum L. - J. exp. mar. Biol. Ecol. 150, 91-105.

Kideys, A. E., Nash, R. D. M. \& Hartnoll, R. G., 1993. Reproductive cycle and energetic cost of reproduction of the neogastropod Buccinum undatum in the Irish Sea. - J. mar. biol. Ass. U.K. 73, $391-403$.

Kohn, A. J., 1968. Microhabitats, abundance and food of Conus on the atoll reefs in the Maldive and Chagos Islands. - Ecology 49, 1046-1062.

Kraeuter, J. N., Castagna, M. \& Bisker, R., 1989. Growth rate estimates for Busycon carica (Gmelin, 1791 ) in Virginia. - J. Shellfish Res. 8 (1), 219-225.

Kubo, I. \& Kondo, K., 1953. Age determination of the Babylonia japonica (Reeve), an edible marine gastropod, basing on the operculum. - J. Tokyo Univ. Fish. 39 (2), 199-207.

Laxton, J. H., 1970. Shell growth in some New Zealand Cymatiidae (Gastropoda: Prosobranchia). J. exp. mar. Biol. Ecol. 4, 250-260.

Macdonald, P. D. M. \& Pitcher, T. J., 1979. Age-groups from size-frequency data: A versatile and efficient method of analyzing distribution mixtures. - J. Fish. Res. Bd Can. 36, 987-1001.

Magalhaes, H., 1948. An ecological study of the snails of the genus Busycon at Beaufort, North Caroline. - Ecol. Monogr. 18, 377-409.

Nielsen, C., 1975. Observations on Buccinum undatum L. attacking bivalves and on prey responses, with a short review on attack methods of other prosobranchs. - Ophelia 13, 87-108.

Ricker, W. E., 1975. Computation and interpretation of biological statistics of fish populations. - Bull. Fish. Res. Bd Can. 191, 1-300.

Santarelli, L. \& Gros, P., 1985. Détermination de l'âge et de la croissance de Buccinum undatum L. (Gastropoda: Prosobranchia) à l'aide des isotopes stables de la coquille et de l'ornementation operculaire. - Oceanologica Acta 8, 221-229.

Sparre, P., 1989. What is the optimum interval class size for length-frequency analysis? - Fishbyte 7 (2), 23.

Sparre, P., Ursin, E. \& Venema, S. C., 1989. Introduction to tropical fish stock assessment. Part 1: Manual. - FAO Fish. tech. Pap. 306.1, 1-337.

Taylor, J. D., 1978. The diet of Buccinum undatum and Neptunea antiqua (Gastropoda: Buccinidae). - J. Conch. 29, 309-318.

Walford, L. A., 1946. A new graphic method describing the growth of animals. - Biol. Bull. mar. biol. Lab., Woods Hole 90, 141-147.

Yamaguchi, M., 1977. Shell growth and mortality rates in the coral reef gastropod Cerithium nodulosum in Pago Bay, Guam, Mariana Islands. - Mar. Biol. 44, 249-263.

Zar, J. H., 1984. Biostatistical analysis. Prentice-Hall, Englewood Cliffs, N. J., 718 pp. 